\title{
Expected and Achieved Benefits of ERP Systems Implementation over Time
}

\author{
Libor Měsíček $^{1}$ (D), Pavel Petrus ${ }^{2}$ (D), Adéla Stránská ${ }^{3}$ \\ ${ }^{1}$ Faculty of Social and Economic Studies, Jan Evangelista Purkyně University in Ústí nad Labem, Moskevská 54, \\ 40096 Ústí nad Labem, Czech Republic \\ 2 Faculty of Education, Jan Evangelista Purkyně University in Ústí nad Labem, České mládeže 8, 40001 Ústí nad Labem, Czech Republic \\ ${ }^{3}$ Arsiqa system s.r.o., Nová 304, 25210 Mníšek pod Brdy, Czech Republic
}

Corresponding author: Libor Měsíček (1.mesicek@ujep.cz)

\begin{abstract}
Today information systems are an inseparable part of all companies. This study deals with the nonfinancial implications occurring while implementing the enterprise resource planning software called AROP in 3 manufacturing companies being in different implementation phases. The work was based on semi-structured interviews, which were supplemented by a questionnaire survey with the management and the employees of the companies. The primary goal was to determine both the expected and the real impacts associated with the introduction of AROP software in the companies. The secondary goal was to determine satisfaction with AROP training in individual companies and to propose countermeasures. It was found that the company using AROP software in the full version confirmed a number of impacts that the companies had expected in the testing phase and in the phase just before the start of the testing phase. Examples of the confirmed impacts are following: merging all information into one system, obtaining previously unknown information or simplifying the work of employees. During the training, some weaknesses were identified, such as the length of the training or the form of the training. Therefore, several recommendations were proposed in order to streamline the implementation of AROP software and improve the training of this system.
\end{abstract}

\section{Keywords}

Information systems, MRP, AROP, Enterprise resource planning, Material requirements planning. 


\section{Introduction}

Information systems are currently one of the essential parts of our daily lives. MRP (Material Requirements Planning) and ERP (Enterprise Resource Planning) are special categories of such information systems. These systems emerged in the 1960s when they initially checked supplies. They later shifted to the planning and directing of production (Hart \& Snaddon, 2014), out of which MRP developed and is still a part of manufacturing companies (Prouty \& Castellina, 2011). MRP can be defined as computer systems that direct the flow of information about material from its production to the customer (Sastim et al., 2006).

Further development of MRP led to the creation of ERP. Sodomka and Klčová (2010, p. 44) define ERP as "an effective tool capable of covering the planning and directing of the main internal business processes (resources and their transformation into outputs), at all levels, from operational to strategic".

The introduction of the MRP or ERP systems into a business should bring a number of advantages such as raising the effectiveness of production, improvement in product quality, and higher productivity as these systems enable the creation and sharing of exact information in time (Agaoglu et al., 2015). Precise and timely information has several positive impacts on a company such as lowering operational and administrative burdens, reducing the amount of staff, shortening the production period, or increasing customer satisfaction (Lipaj \& Davidavičienè, 2013).

On the other hand, a company may not achieve the benefits mentioned above due to the complexity of the software, lack of qualified staff, unrealistic production planning, or insufficient involvement of top management (Sastim et al., 2006). For smaller companies, there is a great risk of not surviving the unsuccessful implementation of these systems (Muscatello et al., 2003).

A necessary condition for achieving the benefits of ERP or MRP is the successful implementation of the system in the company. The most important factors are careful software selection, software analysis, thorough testing and removal of problems identified during testing, sales support, process reorganization, top management support, and employee training (Agaoglu et al., 2015). The main problems during implementation are delayed implementation, employee resistance to changes, transfer of data from previous applications, staff training, and increased difficulty of using the system or connection to existing applications (Helo et al., 2008; Spathis \& Constantinides, 2003).

Since employee competencies and capabilities increase over time, proper training is vital to maximize the usage of ERP system features (Catherine \& Abdurachman, 2018). The users of ERP or MRP have to be trained to operate it correctly. Training is important for obtaining knowledge of the ERP system, which reduces the uncertainty of users and allows them better participation in the implementation project (Najm et al., 2018). In the case of a correct implementation of ERP systems, sales warehouses can be completely removed as desired in just-in-time production systems (Erkayman, 2018).

A research was carried out in Czech manufacturing companies in 2014. The researcher used a questionnaire-based investigation through "28 production companies of all sizes (except microenterprises) with all types of production processes" (Hrusecka, 2014, p. 515). The sample of companies consisted of " 12 respondents with discrete production, 5 respondents with process manufacturing and 11 respondents with line flow manufacturing prevalent" (Hrusecka, 2014, p. 516). The results showed that $48 \%$ of the companies used ERP or MRP. $7 \%$ of the companies used ERP complemented by other special software. $22 \%$ of the companies used complex methods of planning. $23 \%$ of the companies used Microsoft Excel or their own method of planning (Hrusecka, 2014).

The company ARSIQA system, s.r.o. (ARSIQA) deals with the development of ERP and MRP software for the specifics of the Czech Republic. The company ARSIQA offers consultations on implementation and training on their software named AROP (Arsiqa system, 2020). Their software can be adapted to specific 
branches and sizes of companies, as evidenced by their customers in various fields "in the armaments, electrical, footwear, textile or chemical industries, in metal production, design or wood production" (Arsiqa system, 2020).

The AROP software is a complex system designed for middle-sized and larger companies. AROP is suitable for scheduling both piece production (e.g. mechanical engineering) and dose production (e.g. chemical production). It can also handle the planning of material purchases and complete warehouse and quality management (Arsiqa system, 2020).

The ERP software solves only the problem of production of a given product. A company has to deal with the economics of production too. This is solved by the use of accounting software. The ERP and accounting software are independent, but for the sake of production efficiency, they should by connectable. The POHODA software is an accounting and information system for tax management, payroll management, property management, invoice management, and many more (Pohoda, 2020). The POHODA software is designed for the environment of the Czech Republic and thus it has a limited area of use in the Czech Republic (Pohoda, 2020). The POHODA and AROP systems can be connected, which increases productivity in the company.

The primary goal of this work was to determine the expected and the real impacts associated with the implementation of the AROP system in companies in different stages of AROP system implementation. The secondary goal was to determine the satisfaction with AROP training in individual companies and to propose measures to limit weaknesses. Two research questions were defined based on the goals of the work:

- How does the impact on employees differ in various stages of the implementations of AROP system?

- Are the employees and the heads of the companies satisfied with the AROP training?

\section{Methodology}

The interviews and questionnaires about companies were obtained from the qualification work of Adéla Stránská (2020). The research included three companies marked as A, B, and C. Company A deals with mechanical engineering (welding, machining) and it had 93 employees. Company B deals with chemical industry (production of chemicals) and it had 100 employees. Company $\mathrm{C}$ deals with the electrical industry (production of electromagnets) and it had 14 employees.

The answers were analyzed only by descriptive statistics. Quantitative methods could not be used because of the low number of answers. We used only qualitative methods. The interviews were conducted with both the company management and the employees relevant to the AROP system. The company management had their own interview protocol, as shown in Appendix A, and the employees had their own protocol, shown in Appendix B.

In the interview protocol for company management, the first part dealt with basic information about the company and the respondent. The second part dealt with choosing the AROP system and its implementation. The third part dealt with the advantages and disadvantages of the AROP system for a company and for its employees. The fifth part dealt with AROP training.

In the interview protocol for employees, the first part dealt with basic information about the respondent. The second part dealt with the duties of a given respondent connected to the AROP system. The third part dealt with AROP training. The fourth part dealt with experiences with AROP system.

The interviews themselves took place in companies A and B from February to March 2019. In August 2019, the interviews took place in company C. The selection of respondents was determined by their 
availability at the time, their position and knowledge of the AROP system. All interviews were recorded and subsequently transcribed.

The participants set consisted of 9 men and 4 women in the age range of 20 to 60 years. Each company had one interview participant from their management. The number of interviews with employees in company A was 3, in company B it was 4 and in company $\mathrm{C}$ it was 3 . In terms of the positions of the participants in the interview, the following positions were represented: company manager, production technologist, laboratory manager, warehouse accountant, purchasing department employee, supply department employee, trade department employee, sales department employee and production design employee. An overview of information on the conducted interviews is given in Table 1. The shortness of interviews with some employees is given by very short answers to the questions from the interview protocol.

Table 1: Overview of interviews conducted with company management and their employees.

\begin{tabular}{clll}
\hline Company & Position of respondent & Interview length & Protocol \\
\hline A & Director and owner & $21 \mathrm{~min}$. & Appendix A \\
A & Procurement & $6 \mathrm{~min}$. & Appendix B \\
A & Technology and welding & $5 \mathrm{~min}$. & Appendix B \\
& supervision & & \\
A & Trade department & $7 \mathrm{~min}$. & Appendix B \\
B & Financial director & $17 \mathrm{~min}$. & Appendix A \\
B & Production technologist & $9 \mathrm{~min}$. & Appendix B \\
B & Laboratory manager & $12 \mathrm{~min}$. & Appendix B \\
B & Warehouse accountant & $6 \mathrm{~min}$. & Appendix B \\
B & Purchasing & $11 \mathrm{~min}$. & Appendix B \\
C & Company management & $11 \mathrm{~min}$. & Appendix A \\
C & Sales department & $5 \mathrm{~min}$. & Appendix B \\
C & Construction department & $14 \mathrm{~min}$. & Appendix B \\
C & Purchasing department & $7 \mathrm{~min}$. & Appendix B \\
\hline
\end{tabular}

The method of the semi-structured interview was complemented by a questionnaire as well. The purpose of the questionnaire was to confirm or refute opinions from more respondents as well as to get negative opinions that a respondent would otherwise not offer in an interview.

The questionnaire itself was compiled on the basis of the work of Rajan and Baral (2015), who investigated the impact of the implementation of an enterprise information system on company employees. Questions were taken from their studies that concern training and general perception of enterprise information systems. The selection of the first area is given by the phase of implementation of the AROP system. Arguments for this area can be found in literature, as the training of employees is one of the critical factors influencing the successful implementation of enterprise systems (Agaoglu et al., 2015; Rajan \& Baral, 2015).

The questionnaire was sent out by email at the beginning of March 2019 and was received by 38 employees of company A and by 15 employees of company B. In company $\mathrm{C}$ there was no questionnaire process 
carried out as respondents answered the questions during interviews. The number of submitted questionnaires was 8 from company A and 9 from company B. The return rate was $21 \%$ for company $\mathrm{A}$ and $60 \%$ for company B. All recipients who underwent training for AROP system were already using the system or would use the system in the future.

This research examined data from three companies, labeled A, B, and C. An overview of basic information on these companies is shown in Table 2. The individual companies will be presented in the following paragraphs.

Table 2: Overview of basic data on companies participating in the research.

\begin{tabular}{|c|c|c|c|c|c|}
\hline Company & $\begin{array}{l}\text { Number of } \\
\text { employees }\end{array}$ & Field & $\begin{array}{l}\text { Method } \\
\text { used before } \\
\text { AROP } \\
\text { system }\end{array}$ & $\begin{array}{l}\text { Phase of } \\
\text { implementatio } \\
\text { n of AROP } \\
\text { system }\end{array}$ & $\begin{array}{l}\text { Target } \\
\text { status }\end{array}$ \\
\hline A & 93 & $\begin{array}{l}\text { Mechanical } \\
\text { engineering - } \\
\text { welding, } \\
\text { machining }\end{array}$ & $\begin{array}{l}\text { MS Excel + } \\
\text { POHODA }\end{array}$ & $\begin{array}{l}\text { Before starting } \\
\text { the test run }\end{array}$ & $\begin{array}{l}\text { AROP + } \\
\text { POHODA }\end{array}$ \\
\hline B & 100 & $\begin{array}{l}\text { Chemical } \\
\text { industry - } \\
\text { production of } \\
\text { chemicals }\end{array}$ & $\begin{array}{l}\text { MS Excel + } \\
\text { POHODA }\end{array}$ & Trial operation & $\begin{array}{l}\text { AROP + } \\
\text { POHODA }\end{array}$ \\
\hline C & 14 & $\begin{array}{l}\text { Electrical } \\
\text { industry - } \\
\text { production of } \\
\text { electromagnets }\end{array}$ & $\begin{array}{l}\text { Navision + } \\
\text { POHODA }\end{array}$ & Full operation & $\begin{array}{l}\text { AROP + } \\
\text { POHODA }\end{array}$ \\
\hline
\end{tabular}

\subsection{Presentation of individual companies}

The next paragraphs provide a short introduction of the companies. Information about the system used in the given company is mentioned, as well as the reasons for change.

\subsubsection{Introduction of company A}

At the time of the research, company A was planning orders using Microsoft Excel spreadsheets (Microsoft 365, 2020), which were shared among all employees. Along with the spreadsheets, employees passed information to each other in person, and planning took place manually without any software.

Company A had several reasons for the implementation of the AROP system. Since its founding, it has been using the system POHODA (Pohoda, 2020), which is able to perform only elementary production planning. The increase of orders made the necessity of introducing ERP clear so that they would have all production information in one place. After a thorough consideration and analysis of systems on offer, the company decided for a combination of the POHODA and AROP systems.

\subsubsection{Introduction of company B}

At the time of the research, orders were planned only with the help of Microsoft Excel spreadsheets (Microsoft 365, 2020), which were not connected with the POHODA system.

Company B had several reasons for the introduction of the AROP system. At the time of the research, the Purchasing Department was responsible for inventory management, and it was the only department 
being aware of the actual state of the stock. Company B used custom software to calculate its products, but the software's development was already finished. This software was also not linked to purchasing, trading, or accounting. The company wanted to unify all information and also solve the problem with the completed software development. After a thorough analysis of the software available on the market, company B decided for a combination of the POHODA and AROP systems.

\subsubsection{Introduction of company C}

Before the introduction of the AROP system, the planning of orders was done using the software Navision (Navision, 2020). Company $C$ had several reasons for introducing the AROP system. After updating the Navision software, the settings of the system were disrupted. At the same time, Navision did not support Czech legislation. The Navision system was dependent on the Internet, therefore if the network was down or there was any other problem associated with the system, production had to be interrupted. After thorough consideration, company $\mathrm{C}$ decided for a combination of the POHODA and AROP systems.

\section{Results}

The expected impacts of the introduction of the AROP system were investigated in companies A and B. The expected results were not investigated in company $\mathrm{C}$, because company $\mathrm{C}$ was using AROP system in production.

\subsection{Expected impact in company $A$}

The management of company A expects AROP system to bring the positive effects of higher speed, carefulness and flawlessness in order processing. Employees, after the introduction of the AROP system: "... will not be able to perform, as I call it, folk creativity," as stated by the director and owner of the company in an interview (director, personal interview, 7. 3. 2019). Employees will have an exact definition of how they should work; however, the management assumes the employees will not like it.

The management expects the disadvantage of increasing bureaucracy and slowing down during the changes compared to the situation before the AROP system. However, this is a common disadvantage of any system, not just the AROP.

\subsection{Expected impact in company $B$}

The management of company B expects the AROP system to bring positive effects in the availability of more detailed and faster information on the current state of production, production plans for the next few days or weeks, and the state and location of stocks. In an interview, it was literally said: "We expect to have more detailed information and faster information regarding the current state of production. So what is planned for production for the next few days or weeks at most, which is enough for us." (chief financial officer, personal interview, 20. 2. 2019) After the implementation of the AROP system, it will contain all the information, which should facilitate the work of employees and increase the accuracy of calculations of individual products according to production batches.

Another positive impact is expected in the interconnection of the AROP system with the POHODA system, which will unify all data in one place. The Management expects disadvantages for its employees as they will have to record the performance of their work immediately, which they were not used to doing at the time of the research. The company expects to obtain information on the time of individual actions, which it did not have at the time of the research.

\subsection{Real impacts of the introduction of the AROP system}

The positive impacts only begin to be significantly noticeable two years after the introduction of the system and increase over the years (Wieder et al., 2006). In companies A and B, only the negative effects 
of implementation had become apparent at the time of the research, as revealed by the interviews. Among the negative impacts is the increased time burden of employees who have to learn the new system and participate in trainings. This gives them additional work responsibilities. In the testing phase, employees have to do a number of operations in duplicate because they have to perform their work in both the previous system and in the AROP system as well. The company's employees, together with ARSIQA, came up with tailored improvements to the AROP system to suit the company.

The associated additional costs will be reflected in the implementation of any ERP system and cannot be avoided if the risk for the company of failing the system implementation is to be reduced (Agaoglu et al., 2015).

The employees' view of the new system's introduction is also important. When starting to use the new system, the users cannot fully utilize all its advantages nor can have automated working procedures. Subjectively, they get the impression that the new system is inefficient and will burden them with extra work, rather than saving some. This is also reflected in the views of employees of both company A and company B in their answers to the question "Do you consider the AROP system to be useful for your work?" which are shown in Table 3. This view changes as employee knowledge and experience with the AROP system grow as evidenced by both the data in Table 3 and the employees of company C.

Table 3: Employee responses to the question: "Do you consider the AROP system to be useful for your work?"

\begin{tabular}{lcccc}
\hline Response & I agree & I partly agree & I partly disagree & I disagree \\
\hline Company A & 2 & 1 & 0 & 5 \\
Company B & 1 & 2 & 4 & 2 \\
\hline
\end{tabular}

The results in table 3 show that the employees from company A have a more negative attitude to the AROP system than the employees from company B. The reason could be the state of implementation of AROP in the companies. Company A was at the start of implementation, company B was in a testing state. The employees are resistant to changes at their work and they are naturally afraid of the unknown, which was apparent in both companies. Another reason is in the employees' knowledge of similar systems. Most of the employees at company A did not have experience with any similar system, whereas in company B around $70 \%$ of employees did. The knowledge at company B reduces the "fear", which can explain the smaller number in "I disagree" column.

\subsection{Real impacts in company C}

The Company $C$ has been using the AROP system in full operation since 2019, thus it has information on the real impacts of its introduction. The management of company $C$ sees positive effects in the transparency of production, as the employees find the availability of a given component directly in the computer system. The component information is also immediately available to all departments in the company. The positive effects were reflected in the acquisition of important information, such as the actual time needed to produce a given product and the performance of individual employees. This enabled the company to ensure better coordination and production planning. Another positive impact mentioned is the presence of all information in one system, where it is available to all employees. The introduction of the AROP system simplified and accelerated the receipt and dispensing of material into production, using bar codes. Last but not least, the creation of a protocol for each product that company $\mathrm{C}$ produces has been simplified and accelerated. Company $\mathrm{C}$ employees appreciate the Czech language used in the AROP system, savings of production time, and its independence of the internet connection. 
The management of company $\mathrm{C}$ expects further savings in employee capacity and appreciates that this system cannot be circumvented in any way.

\subsection{Training}

In all three companies, the training took place in several stages under the leadership of an executive director from the company ARSIQA.

\subsubsection{Training in company $A$}

The subject of training at company A was technical preparation of production, quality, production planning, and management of work in progress records, production monitoring, production accounting, purchasing, and warehousing. The training was attended mainly by employees from the department of supply, technical preparation of production and welding, trade, and the company management.

According to the interviews, almost all respondents were satisfied with the training, they appreciated the help from the trainer, and would not change anything about the training. Only one employee from the technical preparation department was unsatisfied. This employee had taken part in the training 3 years previously, in which he was annoyed that he could not see the entire order process in the AROP system.

As part of the questionnaire survey, the following questions were given to employees in company A:

1. Did you perceive the trainer as informed, prepared, and experienced?

2. Did the trainer help you understand the AROP system?

3. Did the training cover all the topics necessary for your work?

4. Did the training provide you with all the necessary answers that you subsequently needed?

5. Has your level of understanding of the AROP system improved after the training and has the training helped you solve problems with the use of the AROP system?

Responses to these questions are in Figure 1. The Respondents with disagreeing responses to question no. 4 would like the AROP system to be shown in practice and would like the training to be oriented on a specific company.

Figure 1 shows that one-half of the participants considered the trainer to be informed, prepared, and experienced, while the second half did not. A slightly bigger part of the participants did not think the trainer was helping them understand the AROP system, which can be a consequence of the trainer not covering all necessary topics. The participants did not think every thing they needed was answered during the training. A slightly bigger part of participants did not think the understanding of the AROP system has improved after the training. 


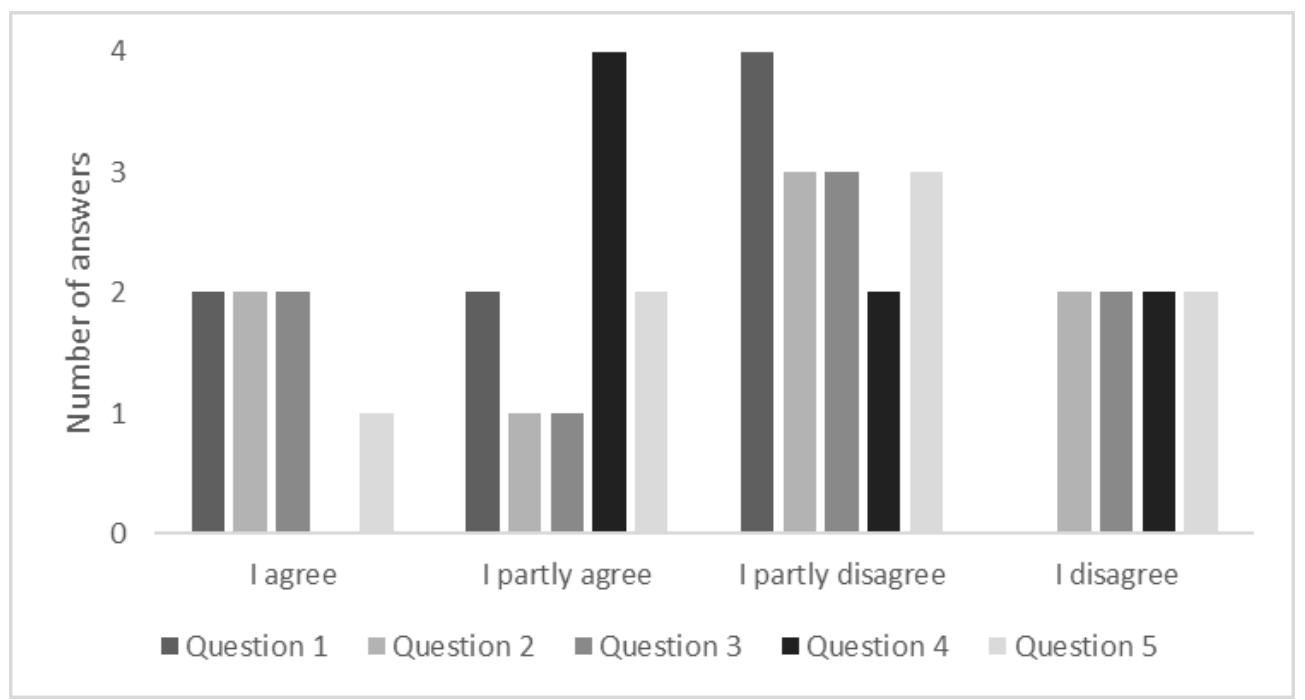

Figure 1: Company A employee responses concerning training.

\subsubsection{Training in company $B$}

Interviews with the management of company B showed that the first encounter with the AROP system was not easy for all employees. They had to get acquainted with new terms in the AROP system, with the form of planning, with different types of plans, etc. This was also confirmed in an interview by a production technologist, who emphasized the need to understand all the terms in order to understand the entire system. This fact necessitated the organization of several multi-hour blocks of training.

All employees completed basic training, which was subsequently expanded to include training focused on specific employees and their positions. The company's management completed all trainings.

In the questionnaire survey, the employees of company B were asked the same questions as the employees of company A. Responses to these questions are in Figure 2.

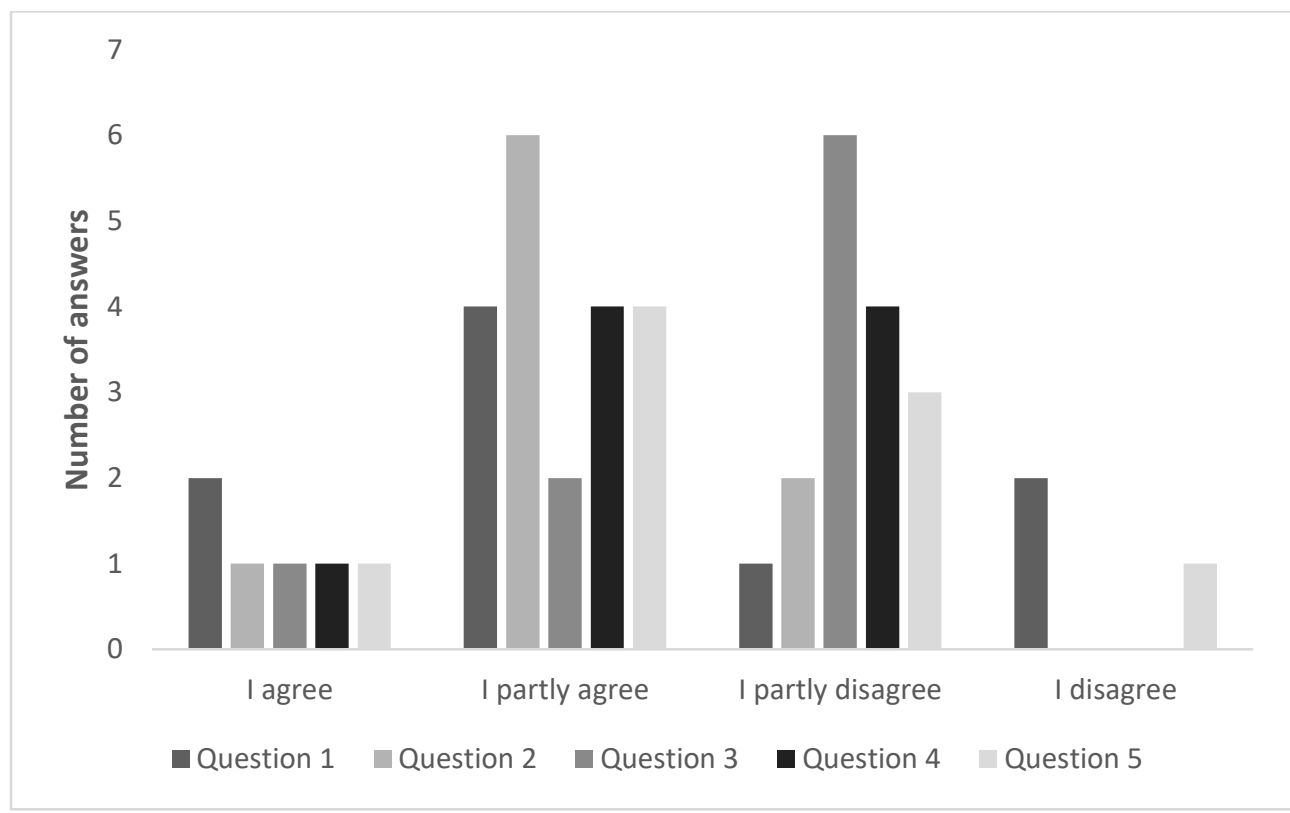

Figure 2: Company B employee responses concerning training. 
The production technologist said in an interview that the training was comprehensive for him and he would not change anything. However, it took him a long time to learn the system, as he had several other work assignments simultaneously. He considers the system to be extensive and would only welcome opportunities for his business to take advantage of it.

According to the head of laboratory, the training spent a lot of time repeating familiar issues, which was tiring and useless. It was not focused on the important issues that the employees had comments about. In the interview, one employee said: “... we had about three or four trainings and it was always two hours of repeating something we seemed to have already known, so it was useless to us. It was unnecessarily long because we repeated issues we already knew, and then it wasn't focused on things we had written comments about..." (head of laboratory, personal interview, 20. 2. 2019). She would like to be shown the whole production process in the AROP system, i.e. from ordering the raw materials to the production of the final product, not just a part of it. This would help her understand the system and coordinate her steps with the overall functionality of the system. The most difficult thing for her was to understand the terms in the AROP system, which collide with the terms familiar in the company.

The warehouse accountant would appreciate a more detailed training. In the interview, she said: “I would certainly imagine the training to be more detailed, more or less for each employee, to be assigned a trainer to lead them in more details." (warehouse accountant, personal interview, 20. 2. 2019).

The purchasing manager would change the inappropriate form of training in which the trainer only lectures and the students record the information. He would prefer communication with the lecturer, who would operatively respond to individual questions, or would find the answer by the next training session.

\subsubsection{Training in company $\mathrm{C}$}

According to the interviews with the company's management and all the employees, everyone was satisfied with the training. The employees from the purchasing department were given all necessary information. After having the opportunity to try the AROP system in a practice mode to further explore it, the understanding has even improved. At the time of the research, however, they have not made full use of it as the system is too extensive.

It was very difficult for the employees of the production design department to absorb all the information about such an extensive software in just a few hours. This was confirmed by a member of the company's management, who would recommend splitting the training into two phases for a better understanding of the system. An employee from the production design department suggested that the training could have taken place directly on the computer so that each employee could try out the system immediately. At the time of the research, the training was only in the form of explaining a lot of information. The employees then tried out the AROP system themselves and in case of any problems, they had to wait for the next training.

\section{Discussion}

To remain competitive, it is necessary, among other things, to implement tools that support production planning and control (Guerra et al., 2014; Sastim et al., 2006). This was also confirmed in this work, as this need was recognized by the management of all three companies examined. Upon the introduction of the AROP system, there are expectations of many positive impacts.

One of the expected positive effects is the merging of data into one system, where it will be available to all employees online. This expectation is confirmed in the work of Spathis and Constantinides (2003). Creating and communicating accurate information brings increased efficiency, as expected by the management of all three companies and confirmed by the literature (Agaoglu et al., 2015; Sriratanaviriyakul et al., 2013). 
The company's management expects a reduction in the operational and administrative burden on employees. This should lead to higher employee satisfaction and better cooperation across all departments. The same conclusion was reached by Spathis and Constantinides (2003), Rajan and Baral (2015) and Martyani et al. (2019).

After the implementation of the AROP system, the warehouse management will be unified, which will lead to the possibility of reducing the state of stock and thus the costs that are tied up in excess stock, confirmed by the work of Prouty and Castellina (2011). This work confirms the work of Sastim et al. (2006), who claim that outputs of MRP systems serve as inputs for other systems. This work deals with the interconnection of the AROP and POHODA systems.

Neither this work nor the companies researched confirmed the impacts mentioned in the work of Guerra et al. (Guerra et al., 2013; Guerra et al., 2014), the flexibility of calculating material requirements, meeting delivery deadlines, flexibility in rescheduling production and minimizing waste. The work of Wieder et al. (2006) offers an explanation, describing positive impacts that appear after a significantly longer period of using MRP and further increase in time.

The importance of training the user was stressed, because the users must have the necessary skills to understand the system's functioning to take full advantage of the system's functionalities. How essential the training is was demonstrated by Maas et al. (2018).

Exact, precise and easily accessible information is an important factor for business today. Companies A and $\mathrm{B}$ expected the AROP system to provide them this feature and stressed this to be the number one requirement. Company $C$ confirmed that the AROP system is able to provide that. Having this information, the company management can make a better decision, better planning and perform more effective production. The AROP system can be connected to the POHODA system, as it was confirmed by company $\mathrm{C}$. This is an important factor, enabling an increase of productivity and effectivity in a company within the area of the Czech Republic. The mentioned benefits could not be achieved without trained and motivated employees who are open to change. However, the employees are mostly resistant to changes, which is a common human nature. They are afraid of a new unknown system. They do not want to change the style of their work and they worry that it could bring them more disadvantages than benefits. All these worries and resistance have to be minimized during the training with maximal support from the management of the company. Both the trainer and the management of the company have to show clearly the benefits which the AROP system brings the employees. The AROP system itself is useful in this way, because it is localized in the Czech language, which is naturally friendly to users.

The study has many limitations. One is given by the chosen AROP system, which is not so widely spread as, for example, SAP. Another limitation is given by the three different implementation stages of the AROP system in the company, which limits the number of companies for this study. The presented companies have their business in absolutely different areas, which can be another important factor for this study. The number of eligible employees was limited by their work with the AROP system and by the total number of employees in a given company.

The interviews and questionnaires were limited by the number of possible participants (e.g. just 8 people in the company interact with the AROP system). The interviews were carried out during the working hours of the employees, which limits the length and information value of the interviews.

\subsection{Comparison between expected and real impacts}

The head of company A expected the AROP software to provide speed, precision and faultlessness. The employees of company A have to do their work exactly and they will be limited in their "creativity" at work. 
The head of company B expected AROP software to provide more detailed and faster production information. The head of company B expected plans, production plans for next few days and information on what is currently being produced. They expected immediate access to information about stock level and its location. Another expectation was of a more accurate calculation of individual products according to production batches. The employees will have to record the performance of their work immediately, which is going to provide the head of the company with new important information.

The head of company $\mathrm{C}$ confirms the accessibility of information about production to all employees. The head of company $\mathrm{C}$ got exact information about the time of production of a given product as well as information about the performance of individual employees. The administrative burden was lowered because the AROP system is able to generate reports about given products. Another advantage is that AROP cannot be circumvented in any way.

We can identify deficiencies in the implementation of the AROP system across all researched companies:

- In the companies there is no employee fully in charge of the AROP system implementation.

- The requirements for the AROP system are communicated through the executive director, who formulated the requirements the to programmers in ARSIQA.

- The design of the AROP system looks like DOS, which does not increase trust in the AROP system.

We can identify deficiencies in the AROP system training across all researched companies:

- The employees did not get the whole picture of the AROP system at the first training session.

- The training used the frontal method, which is not useful for training a software in general.

- The time lag between trainings was too long, causing the employees to forget a lot of previously acquired information.

- The employees did not consider the training to be useful enough for their work.

- The manual to the AROP system is not user friendly.

- The terms in the AROP system differ from the terms commonly used in the companies.

- The facilitator did not get immediate feedback after the end of a training session.

The effects mentioned above appear in the growth phase of implementation, thus the effects in company A represent the benefits of pre-implementation phase; company $B$ represents the benefits of a trial phase and company $\mathrm{C}$ represents the benefits of full operation.

\subsection{Suggestions and recommendations}

Based on the identified deficiencies, the following recommendations concerning implementation were proposed:

- To appoint a person in the company who will have an explicit obligation to implement the AROP system. Introducing such person will speed up and simplify the implementation process.

- In the implementation and testing phase of the AROP system, the ARSIQA programmer who is in charge of the company should communicate directly with the company. This shall prevent a number of misunderstandings between the company and the programmers.

- To improve the graphic design of the AROP system to match current trends. This will allow the AROP system to be better presented to potential customers and will be appreciated by existing ones.

Based on the obtained data, the following recommendations concerning training were proposed:

- At the first AROP training, show its functionalities completely in accelerated and simplified form. This will allow the users to get an overview of its operation in wider contexts. 
- Change the form of the training, or at least part of it, so that each user can have access to a computer. This will allow the trainer to respond immediately to any possible questions and suggestions from the users. The training will be more engaging with a greater impact on the users.

- Try to minimize the time lag between individual trainings. This will allow the trainer to spend less time on repetition and to minimize users' forgetting.

- Dedicate some part of the training to helping users streamline their work in the AROP system. This will lead to better acceptance of the AROP system by the users and at the same time to an improvement in the services of ARSIQA.

- Adjust the AROP manual so that it is understandable to a novice user who has never worked with a similar system. This will bring benefits to users as well as to the trainer, who will be less exposed during subsequent queries.

- Create a dictionary of terms associated with the AROP system. This will allow users to clarify the term more quickly and match different terminologies in the company and in AROP system.

- The trainer should ask the users for feedback at the end of each training. This will improve the skills of the trainer and thus improve the services of ARSIQA.

\section{Conclusion}

This work deals with non-financial implications occurring while implementing the enterprise resource planning software called AROP in 3 manufacturing companies in different implementation phases. The work was based on semi-structured interviews, which were supplemented by a questionnaire survey with the management and the employees of the companies. The primary goal of the work was to determine both the expected and the real impacts associated with the implementation of AROP in the companies. The secondary goal was to determine satisfaction with AROP training in individual companies and to propose improvements. It was found that the company using AROP software in the full version confirmed a number of impacts that the companies had expected in the testing phase and in the phase just before the start of the testing phase. The examples of the confirmed impacts are following: merging all information into one system, obtaining previously unknown information or facilitating the work of employees.

Concerning the training, weaknesses such as length of training or the form of training were identified. Therefore, several recommendations were proposed in order to streamline the implementation of the AROP software and improve the training of this system. An example of a recommendation for implementation is the determination of a person in the company who will be in charge of the implementation of the AROP software. An example of training recommendations is to conduct computer training.

\section{Additional Information and Declarations}

Acknowledgements: We would like to thank the company ARSIQA and their customers for their cooperation and for providing information and time.

Conflict of Interests: Adéla Stránská is employee of the company ARSIQA. Other authors declare no conflict of interest.

Author Contributions: L.M.: Conceptualization, Formal analysis, Methodology, Supervision, Project administration, Writing - review \& editing. P.P.: Methodology, Writing - original draft, Visualization, A.S.: Data curation, Formal analysis, Investigation, Methodology.

Data Availability: The data that support the findings of this study are available from the corresponding author. 


\section{Appendix A}

\section{Questions for the management of companies implementing the AROP system}

Basic information about the company and the respondent:

1) What is the subject of your company's activity?

2) How many employees work in the company? How many of them work with the AROP system?

3) What is your position in the company?

Questions related to AROP system implementation:

4) How was the planning and management of production arranged before the introduction of the AROP system? What were the advantages and disadvantages of such arrangement of production planning and management?

5) When did you decide to implement the AROP system?

6) Why did you choose the AROP system?

7) Which phase of the implementation is your company currently in?

8) Has the current implementation of the AROP system taken place without complications? Have you been satisfied with the implementation process?

9) What advantages and disadvantages did you expect the introduction of the AROP system would bring the company? What advantages and disadvantages did you expect the introduction of the AROP system would bring the employees?

10) What advantages and disadvantages did the introduction of the AROP system really bring the company? What advantages and disadvantages did the introduction of the AROP system really bring the employees?

11) Has the productivity of your employees improved after introducing the system?

12) What would you change about the AROP system?

13) How do you perceive the AROP system in general - is it difficult to understand? Is it easy to operate?

14) When did you complete the AROP training? Who trained you? What was the subject of the training?

15) How satisfied were you with the AROP training? What would you change about the training?

16) Did it take you long to learn the system?

17) If you have any problems with the AROP system, who do you contact? Are you satisfied with the assistance provided?

18) Do you have experience with another information system?

19) Is your AROP system connected to another system?

20) Do you have any additional comments on the AROP system? 


\section{Appendix B}

\section{Questions for the employees of companies implementing the AROP system}

Basic information about the respondent:

1) What department do you work for in the company?

2) What is your scope of work?

3) What is your age?

Questions related to AROP system implementation:

4) How did you perform your work duties before implementing the AROP system?

5) Were you satisfied with the method you used to perform your job duties before?

6) Do you have experience with another information system of a similar type? If so, do you consider the AROP system to be a better information system?

7) When did you complete the AROP training? Who trained you? What was the subject of the training?

8) How satisfied were you with the AROP training - its completeness, understanding, length, detail, awareness of the trainer and other comments on the training? What would you change about training? What else would you need to be shown?

9) Did it take you a long time to learn how to work with the system? Was it difficult to learn the system? What was the most difficult?

10) If you have any problems with the AROP system, do you know who to contact? Who are you contacting? Is the help provided immediately? Are you satisfied with the help provided?

11) Is it less time-consuming to perform your regular work duties now that you are using the AROP system? Do you make fewer mistakes using AROP system?

12) How do you perceive the AROP system - is it difficult to understand? Is it easy to operate? Are you performing too much mechanical operations? Is it useful for your work? Has your work productivity increased?

13) Are there any problems connected with the system? What exactly are these problems?

14) What would you change about the system?

15) Is the AROP system compatible with the company's IT infrastructure?

16) Estimate what percentage of working time you use the AROP system. Which parts do you use the most? What are you satisfied or dissatisfied with?

17) Do you have any additional comments on the AROP system?

\section{References}

Agaoglu, M., Yurtkoru, E. A., \& Ekmekci, A. K. (2015). The effect of ERP implementation CSFs on business performance: an empirical study on users' perception. In Proceedings of the 4th International Conference on Leadership, Technology, Innovation and Business Management (pp. 35-42). Elsevier. https://doi.org/10.1016/j.sbspro.2015.11.326

Arsiqa system. (2020, September 8). Arsiqa system. http://www.arsiqa.cz/

Catherine, C., \& Abdurachman, E. (2018). ERP System Adoption Analysis Using TOE Framework in Permata Hijau Group (PHG) Medan. International Journal of Enterprise Information Systems, 14(3), 91-105. https://doi.org/10.4018/ijeis.2018070105 
Erkayman, B. (2018). Transition to a JIT production system through ERP implementation: a case from the automotive industry. International Journal of Production Research, 57(17), 5467-5477. https://doi.org/10.1080/00207543.2018.1527048

Guerra, R. M. de A., Schuster, J. V., \& Tondolo, V. A. G. (2013). Implantação De Um Modelo De Mrp Em Uma Empresa De Médio Porte Do Setor Moveleiro. Revista Gestão Industrial, 9(4). https://doi.org/10.3895/s1808-04482013000400011

Guerra, R., Silva, M., \& Tondolo, V. (2014). Material Requirements Planning: tool to improve production planning and control. Revista Gestão Da Produção, Operações e Sistemas, 9(3), 43-60. https://doi.org/10.15675/gepros.v9i3.1075

Hart, C. A., \& Snaddon, R. D. (2014). The Organisational Performance Impact of ERP Systems On Selected Companies. The South African Journal of Industrial Engineering, 25(1), 14. https://doi.org/10.7166/25-1-615

Helo, P., Anussornnitisarn, P., \& Phusavat, K. (2008). Expectation and reality in ERP implementation: consultant and solution provider perspective. Industrial Management \& Data Systems, 108(8), 1045-1059. https://doi.org/10.1108/02635570810904604

Hrusecka, D. (2014). Process Innovation as a Necessary Condition for Successful Implementation of a New Production Planning System. In Proceedings of the 9th European Conference on Innovation and Entrepreneurship (pp. 514-521). ACPI.

Lipaj, D., \& Davidavičienè, V. (2013). Influence of information systems on business performance. Mokslas - Lietuvos Ateitis, 5(1), 38-45. https://doi.org/10.3846/mla.2013.06

Maas, J.-B., Van Fenema, P. C., \& Soeters, J. (2018). Post-Implementation ERP Usage: A Longitudinal Study of the Impact of Control and Empowerment. Information Systems Management, 35(4), 330-347. https://doi.org/10.1080/10580530.2018.1503804

Martyani, E., Rohayani, H., Kurniawan, E., \& Febrianti, H. (2019). Analysis and Information System Planning of Material Requirement Planning Web. Journal of Physics: Conference Series, 1230, no. 012022. https://doi.org/10.1088/1742$6596 / 1230 / 1 / 012022$

Microsoft 365. (2020, September 8). Microsoft 365. https://www.microsoft.com/cs-cz/microsoft-365

Muscatello, J. R., Small, M. H., \& Chen, I. J. (2003). Implementing enterprise resource planning (ERP) systems in small and midsize manufacturing firms. International Journal of Operations \& Production Management, 23(8), 850-871. https://doi.org/10.1108/01443570310486329

Najm, N. A., Aboyassin, N., Said, K. R. M., \& Al-Lozi, E. (2018). The Impact of Change Management on ERP System Outcomes: A Case of Jordanian Pharmaceutical Companies. Journal of Applied Economics and Business Research, 8(2), 93-108.

Navision. (2020, September 8). Microsoft Dynamics 365 Business Central. https://www.konicaminoltaits.cz/byznysaplikace/microsoft-dynamics-365-for-businesscentral/?gclid=EAlalQobChMltoSQkMrJ6gIVGed3Ch3DqgrwEAAYASAAEgJvEfD BwE

Pohoda. (2021, February 28). Ekonomický a účetní program POHODA 2021. https://www.stormware.cz/pohoda/

Prouty, K., \& Castellina, N. (2011). To ERP or Not to ERP: In Manufacturing, It Isn't Even a Question. Aberdeen Group.

Rajan, C. A., \& Baral, R. (2015). Adoption of ERP system: An empirical study of factors influencing the usage of ERP and its impact on end user. IIMB Management Review, 27(2), 105-117. https://doi.org/10.1016/j.iimb.2015.04.008

Sastim, O., Koroglu, S., Yuzukurmizi, M., \& Ersoz, S. (2006). Using Artificial Intellingece in Material Requirement Planning. In Proceedings of 5th International Symposium on Intelligent Manufacturing Systems (pp. 339-345). Sakarya University.

Sodomka, P., \& KIčová, H. (2010). Informační systémy v podnikové praxi. Computer Press.

Spathis, C., \& Constantinides, S. (2003). The usefulness of ERP systems for effective management. Industrial Management \& Data Systems, 103(9), 677-685. https://doi.org/10.1108/02635570310506098

Sriratanaviriyakul, N., Nkhoma, M., \& Pham, H. (2013). Kinik-Thai: Material Requirement Planning System. Journal of Information Technology Education: Discussion Cases, 2, no. 7. https://doi.org/10.28945/1878

Stranska, A. (2020). Dopady zavedení systému AROP ve výrobním podniku. Bachelor thesis. Jan Evangelista Purkyně University in Ústí nad Labem.

Wieder, B., Booth, P., Matolcsy, Z. P., \& Ossimitz, M. (2006). The impact of ERP systems on firm and business process performance. Journal of Enterprise Information Management, 19(1), 13-29. https://doi.org/10.1108/17410390610636850

Editorial record: The article has been peer-reviewed. First submission received on 11 September 2020. Revisions received on 12 December 2020, 8 March 2021 and 19 April 2021. Accepted for publication on 22 April 2021. The editor in charge of coordinating the peer-review of this manuscript and approving it for publication was Michal Dolezel (D).

Acta Informatica Pragensia is published by Prague University of Economics and Business, Czech Republic.

ISSN: 1805-4951 